\title{
Early Recurrence and Cancer Death After Trimodal Therapy for Esophageal Squamous Cell Carcinoma
}

\author{
YOICHI HAMAI ${ }^{1}$, MANABU EMI $^{1}$, YUTA IBUKI ${ }^{1}$, YUJI MURAKAMI ${ }^{2}$, \\ IKUNO NISHIBUCHI ${ }^{2}$, YASUSHI NAGATA ${ }^{2}$, TAKAOKI FURUKAWA ${ }^{1}$, \\ TOMOAKI KUROKAWA ${ }^{1}$, MANATO OHSAWA ${ }^{1}$ and MORIHITO OKADA ${ }^{1}$ \\ ${ }^{1}$ Department of Surgical Oncology, Research Institute for Radiation Biology and Medicine, \\ Hiroshima University, Hiroshima, Japan; \\ ${ }^{2}$ Department of Radiation Oncology, Institute of Biomedical and Health Sciences, \\ Hiroshima University, Hiroshima, Japan
}

\begin{abstract}
Background/Aim: Although locally advanced esophageal squamous cell carcinoma (ESCC) can be controlled and survival can be prolonged by neoadjuvant chemoradiotherapy (NCRT) followed by surgery (trimodal therapy), some patients still develop early recurrence and die of cancer even after such intensive therapy. The present study aimed to determine the factors associated with early recurrence and cancer death for patients with ESCC treated by trimodal therapy. Patients and Methods: We evaluated risk factors for recurrence within 6 months, as well as cancer death within 1 year based on data from 141 patients with ESCC who underwent NCRT followed by curative esophagectomy. Results: The carcinoembryonic antigen level before treatment, postoperative complications, pathology after neo-adjuvant therapy $(y p T, y p N)$, lymphatic invasion, venous invasion and pathological response of the primary tumor were significant factors in a comparison of patients with and without early recurrence. Multivariate analysis subsequently selected ypN $[y p N, 0 / 1$ vs. $2 / 3$; hazard ratio $(H R)=4.13,95 \%$ confidence interval $(C I)=1.25-13.66 ; p=0.02]$ as an independent covariate for early recurrence. Postoperative complications, ypT, ypN, poorer tumor differentiation, lymphatic invasion and venous invasion were significant factors in a comparison of patients with and without early cancer death. Multivariate analysis subsequently selected postoperative complications of grade $\geq 3 b$ (vs. $<3 b$ ) defined according to the Clavien-Dindo classification $(H R=5.9,95 \% C I=1.53-23.47 ; p=0.01)$ and
\end{abstract}

Correspondence to: Yoichi Hamai, MD, Ph.D., Department of Surgical Oncology, Hiroshima University, 1-2-3 Kasumi, MinamiKu, Hiroshima, 734-8551, Japan. Tel: +81 822575869, Fax: +81 822567109, e-mail: yyhamai@hotmail.com

Key Words: Chemoradiation, complication, esophagus, lymph node, vascular invasion. venous invasion (vs. without: $H R=4.80,95 \% C I=1.21-19.14$; $p=0.03$ ) as independent covariates for early cancer death. Conclusion: Further reduction of postoperative complications are needed after NCRT for patients with ESCC. Meticulous surveillance and postoperative adjuvant therapy should be considered for patients with risk factors for early recurrence and cancer death.

Neoadjuvant therapy is currently the standard of care in locally advanced esophageal cancer because randomized studies have shown a significant survival benefit. Trimodal therapy comprising neoadjuvant chemotherapy, radiotherapy and surgery is frequently needed for local control and to improve the survival of patients with locally advanced esophageal cancer (1-3). Although the survival of patients with esophageal cancer has been improved, some still develop recurrence and die of cancer even after curative-intent procedures and intensive treatment. Therefore, the reported range of the 5-year survival rates of patients with locally advanced esophageal cancer after trimodal therapy is $30-50 \%(2-6)$.

Some studies have found that patients with esophageal cancer develop early recurrence or die of cancer ever after curative esophagectomy (7-14). However, to our knowledge, risk factors for early recurrence and early cancer death after trimodal therapy for locally advanced esophageal squamous cell carcinoma (ESCC) have never been investigated. The present study aimed to determine risk factors that influence early recurrence as well as early cancer death after neoadjuvant chemoradiotherapy (NCRT) followed by curativeintent esophagectomy in patients with locally advanced ESCC.

\section{Patients and Methods}

Patients. Patients defined as having performance status 0 or 1 according to the Eastern Cooperative Oncology Group criteria (15) received NCRT and underwent surgery if the cancer in the 
esophagus or gastroesophageal junction was resectable, or if a tumor was more deeply invasive than cT2, positive for lymph node (LN) metastasis $(\mathrm{cN}+)$ or resectable supraclavicular $\mathrm{LN}$ metastasis (cM1 LYM). Five patients with cT4 primary tumors that had been reduced and thus rendered potentially resectable after NCRT underwent esophagectomy.

We reviewed 155 consecutive patients with ESCC who underwent NCRT followed by esophagectomy at our Institution between September 2003 and July 2016. Two patients with tumors in the cervical esophagus, 10 with incomplete resection (R2) and two with unrelated death within 1 year of esophagectomy were excluded. Therefore, we assessed data from 141 patients with locally advanced ESCC included in our surgical database who underwent NCRT followed by curative esophagectomy.

Table I shows the characteristics of the patients. The clinicopathological profiles of the tumors were based on the seventh edition of the TNM Classification of Malignant Tumors (16). Postoperative morbidity was graded from 0 to 5 based on the Clavien-Dindo classification of surgical complications $(17,18)$. The Institutional Review Board at Hiroshima University approved this study (Approval number: E-1501).

NCRT and surgery. NCRT and surgery comprised concurrent radiotherapy (40 Gy in 20 fractions) and chemotherapy with 5fluorouracil and either docetaxel or cisplatin or a combination of both, as described elsewhere $(4,5,19-23)$. The chemotherapy regimen between 2003 and 2007 consisted of docetaxel combined with 5fluorouracil and that since 2008 has consisted of standard doses of cisplatin and 5-fluorouracil. Patients with elevated serum creatinine were treated with nedaplatin instead of cisplatin. Some patients were treated with docetaxel combined with cisplatin and 5-fluorouracil starting from 2009. The chemotherapy regimens were docetaxel/5fluorouracil, cisplatin/5-fluorouracil, docetaxel/cisplatin/5-fluorouracil, or nedaplatin/5-fluorouracil in 34 (24.1\%), 85 (60.3\%), 18 (12.8\%) and four $(2.8 \%)$ patients, respectively.

Surgery was scheduled for all patients at 4 to 8 weeks after completing NCRT. All patients underwent open transthoracic or thoracoscopic esophagectomy and at least two-field (thoracic and abdominal fields) LN dissection. Esophageal cancer in the upper and middle third of the thoracic esophagus, and LN metastasis in the superior mediastinum were essentially treated by cervical lymphadenectomy. A gastric tube or colonic conduit was subsequently lifted via the posterior mediastinal or retrosternal route for cervical anastomosis with the esophagus.

Pathological assessment. Resected esophageal and LN specimens were fixed in formalin immediately after surgery. All areas that were thought to be primary tumors before treatment were cut into $5 \mathrm{~mm}$ sections, embedded in paraffin and stained with hematoxylin-eosin. The residual tumor and tumor depth were pathologically examined. A pathological complete response (pCR) of a primary tumor was defined as no evidence of viable cancer cells. Specific immunostaining (D2-40) and elastica van Gieson stain were routinely applied, along with standard hematoxylin and eosin staining, to evaluate lymphatic and venous invasion, respectively. All LNs were cut along the longest axis and stained with hematoxylin-eosin, then examined for metastases.

Follow-up protocol and definition of early recurrence and death. All patients underwent postoperative medical and blood examinations and computed tomography imaging every 3-4 months for at least 2 years
Table I. Patient characteristics.

\begin{tabular}{|c|c|}
\hline Parameter & $\mathrm{n}=141$ \\
\hline \multicolumn{2}{|l|}{ Age, years } \\
\hline Mean \pm SD & $62.9 \pm 8.1$ \\
\hline \multicolumn{2}{|l|}{ Gender, n (\%) } \\
\hline Male & $122(86.5)$ \\
\hline Female & $19(13.5)$ \\
\hline \multicolumn{2}{|l|}{ ECOG PS, n (\%) } \\
\hline 0 & $129(91.5)$ \\
\hline 1 & $12(8.5)$ \\
\hline \multicolumn{2}{|l|}{ Primary tumor location, n (\%) } \\
\hline Upper third & $27(19.1)$ \\
\hline Middle third & $71(50.4)$ \\
\hline Lower third and esophagogastric junction & $43(30.5)$ \\
\hline \multicolumn{2}{|l|}{$\mathrm{cT}, \mathrm{n}(\%)^{*}$} \\
\hline 1 & $2(1.4)$ \\
\hline 2 & $19(13.5)$ \\
\hline 3 & $115(81.6)$ \\
\hline 4 & $5(3.5)$ \\
\hline \multicolumn{2}{|l|}{$\mathrm{cN}, \mathrm{n}(\%)^{*}$} \\
\hline 0 & $32(22.7)$ \\
\hline 1 & $78(55.3)$ \\
\hline 2 & $29(20.6)$ \\
\hline 3 & $2(1.4)$ \\
\hline \multicolumn{2}{|l|}{$\mathrm{cM}, \mathrm{n}(\%) * \#$} \\
\hline 0 & $123(87.2)$ \\
\hline 1 & $18(12.8)$ \\
\hline \multicolumn{2}{|l|}{ cStage, n $(\%)^{*}$} \\
\hline IB & $6(4.3)$ \\
\hline II & $30(21.3)$ \\
\hline III & $87(61.7)$ \\
\hline IV & $18(12.8)$ \\
\hline \multicolumn{2}{|l|}{ ypT, n $(\%)^{* *}$} \\
\hline 0 & $54(38.3)$ \\
\hline 1 & $17(12.1)$ \\
\hline 2 & $26(18.4)$ \\
\hline 3 & $40(28.4)$ \\
\hline 4 & $4(2.8)$ \\
\hline \multicolumn{2}{|l|}{$\mathrm{ypN}, \mathrm{n}(\%)^{* *}$} \\
\hline 0 & $80(56.7)$ \\
\hline 1 & $41(29.1)$ \\
\hline 2 & $16(11.3)$ \\
\hline 3 & $4(2.8)$ \\
\hline \multicolumn{2}{|l|}{ ypM, n (\%)**\# } \\
\hline 0 & 135 (95.7) \\
\hline 1 & $6(4.3)$ \\
\hline \multicolumn{2}{|l|}{ ypStage, $\mathrm{n}(\%)^{* *}$} \\
\hline 0 & $41(29.1)$ \\
\hline I & $19(13.5)$ \\
\hline II & $46(32.6)$ \\
\hline III & $29(20.6)$ \\
\hline IV & $6(4.3)$ \\
\hline
\end{tabular}

SD, Standard deviation; ECOG PS: Eastern Cooperative Oncology Group performance status. *Pretherapeutic/**pathological staging according to TNM Classification, seventh edition (16). \#Supraclavicular lymph node metastasis.

after surgery and every 6 months from 3 years thereafter and annual endoscopy. More detailed examinations proceeded if any symptoms were reported. After 5 years, almost all survivors attended an 
outpatient clinic for annual health checks. Recurrence was diagnosed by radiology and, when possible, by cytology or histology. Early recurrence was defined as arising within 6 months after surgery (7), and early cancer death as occurring within 1 year after surgery as described elsewhere (8-12).

Statistical analysis. Categorical variables were analyzed using chisquare tests, and continuous variables were analyzed using unpaired $t$-tests. Covariates with $p<0.05$ in the univariate analysis were entered into logistic multivariate analyses to select independent factors for early recurrence and early cancer death. Survival data were analyzed using Kaplan-Meier curves and compared using logrank tests. Recurrence-free survival (RFS) was defined as the time elapsed from the date of surgery until the first event (recurrence or death from any cause), or the most recent follow-up. Overall survival (OS) was defined as the time elapsed from the date of surgery until death from any cause or the most recent follow-up. All patients who remained alive were followed-up for at least 5 years after surgery. At the time of the outcome analysis, 49 patients remained alive and were followed-up for a median of 91.7 (range=30.1-165.3) months after surgery. All data were statistically analyzed using SPSS software version 20.0 (IBM Corporation, Armonk, NY, USA).

\section{Results}

Comparison of clinicopathological factors between patients with and without early recurrence and early cancer death. Table II shows a comparison of patients with and without early recurrence, as well as those with and without early cancer death. Disease recurred after trimodal therapy in 61 $(43.3 \%)$ patients, among whom cancer recurred within 6 months after NCRT followed by esophagectomy in 29 $(47.5 \%)$. Furthermore, $21(34.4 \%)$ out of the 61 patients with recurrence died of esophageal cancer within 1 year after NCRT followed by esophagectomy.

Various clinicopathological factors were compared between patients with and without early recurrence. This comparison showed that increasing carcinoembryonic antigen levels before treatment $(p=0.02)$, severe postoperative complications (Clavien-Dindo classification $\geq 3 \mathrm{~b}, p=0.03$ ), pathology after neo-adjuvant therapy yp $\mathrm{T}$ $(2 / 3 / 4, p=0.01)$ and ypN $(2 / 3, p<0.0001)$, lymphatic invasion $(p<0.0001)$, venous invasion $(p=0.004)$ and lack of pathological complete response ( $\mathrm{pCR}$ ) of the primary tumor $(p=0.03)$ were significantly associated with early recurrence.

Furthermore, a comparison of clinicopathological parameters between patients who died early and those who did not found that severe postoperative complications (Clavien-Dindo classification $\geq 3 \mathrm{~b}, p=0.002)$, ypT $(2 / 3 / 4, p=0.03)$, ypN $(2 / 3$, $p=0.001$ ), tumor differentiation (poorly differentiated, $p=0.02$ ), lymphatic invasion $(p=0.01)$ and venous invasion $(p=0.001)$ were significant factors associated with early cancer death.

Multivariate analysis of clinicopathological factors associated with early recurrence and early cancer death. Table III shows the results of multivariate analyses of factors that were significant in univariate analyses for early recurrence and early cancer death. Multivariate analysis selected ypN 2/3 (hazard ratio $(\mathrm{HR})=4.13,95 \%$ confidence interval $(\mathrm{CI})=1.25-13.66$; $p=0.02$ ) as an independent covariate for early recurrence. Furthermore, multivariate analysis selected postoperative complications of grade $\geq 3 \mathrm{~b}$ according to the Clavien-Dindo classification $(\mathrm{HR}=5.99 ; 95 \% \mathrm{CI}=1.53-23.47 ; p=0.01)$ and venous invasion $(\mathrm{HR}=4.80 ; 95 \% \mathrm{CI}=1.21-19.14 ; p=0.03)$ as independent covariates for early cancer death.

Rates of early recurrence and cancer death in patients with risk factors. Table IV shows the relationships between early recurrence and cancer death and their risk factors. Twelve $(60.0 \%)$ and $17(14.0 \%)$ patients with ypN2/3 $(n=20)$ and with ypN0/1 $(\mathrm{n}=121)$, respectively, developed early recurrence $(p<0.0001)$.

Six $(42.9 \%)$ and $15(11.8 \%)$ patients with $(n=14)$ and without $(\mathrm{n}=127)$ postoperative complications grade $\geq 3 \mathrm{~b}$ according to the Clavien-Dindo classification, respectively, succumbed to early cancer death $(p=0.002)$. Seven $(41.2 \%)$ and $14(11.3 \%)$ patients with $(n=17)$ and without $(n=124)$ venous invasion, respectively, also succumbed to early cancer death $(p=0.001)$. Furthermore, $12(40.0 \%)$ and nine $(8.1 \%)$ patients with $(\mathrm{n}=30)$ postoperative Clavien-Dindo classification $\geq 3$ b complications with/without venous invasion and without both risk factors $(n=111)$ for early cancer death, respectively, succumbed to early cancer death $(p<0.0001)$.

Survival according to risk factors for early recurrence and early cancer death. The 5-year RFS rates for patients with and without risk factors for early recurrence were $15.0 \%$ and $52.6 \%$ respectively (ypN2/3 vs. $0 / 1, p<0.0001$; Figure $1 \mathrm{~A}$ ), and the corresponding 5-year OS rates were $15.0 \%$ and $56.9 \%$, respectively $(p<0.0001)$ (Figure 1A). Furthermore, the 5-year RFS rates for patients with and without risk factors for early cancer death were $23.3 \%$ and $53.7 \%$ respectively (with Clavien-Dindo grade $\geq 3 \mathrm{~b}$ postoperative complications with/without venous invasion vs. without both: $p=0.0004)$, and the corresponding 5-year OS rates were $29.1 \%$ and $56.7 \%$, respectively $(p=0.001)$ (Figure 1B).

\section{Discussion}

Patients with locally advanced esophageal cancer often undergo trimodal therapy, comprising NCRT followed by surgery (1-3). However, some patients develop early recurrence and succumb to cancer death even after such curative-intent and highly intensive treatment. The present study assessed factors associated with early recurrence and cancer death in a uniform cohort of patients with locally advanced ESCC who underwent NCRT and subsequent curative surgery with adequate lymph node dissection. Univariate and multivariate 
Table II. Comparison between patients with and without early recurrence or early cancer death.

\begin{tabular}{|c|c|c|c|c|c|c|c|}
\hline \multirow[t]{2}{*}{ Factors } & & \multicolumn{3}{|c|}{ Early recurrence } & \multicolumn{3}{|c|}{ Early cancer death } \\
\hline & & Yes $(n=29)$ & No $(n=112)$ & $p$-Value & Yes $(n=21)$ & No $(n=120)$ & $p$-Value \\
\hline \multicolumn{8}{|l|}{ Pretherapeutic } \\
\hline Age, years & Mean \pm SD & $62.1 \pm 8.4$ & $63.2 \pm 8.0$ & 0.52 & $62.2 \pm 9.4$ & $63.1 \pm 7.9$ & 0.65 \\
\hline \multirow[t]{2}{*}{ Gender } & Male & $24(82.8)$ & $98(87.5)$ & 0.51 & $17(81.0)$ & $105(87.5)$ & 0.42 \\
\hline & Female & $5(17.2)$ & $14(12.5)$ & & $4(19.0)$ & $15(12.5)$ & \\
\hline \multirow[t]{2}{*}{ ECOG PS } & 0 & $27(93.1)$ & $102(91.1)$ & 0.73 & $19(90.5)$ & $110(91.7)$ & 0.86 \\
\hline & 1 & $2(6.9)$ & $10(8.9)$ & & $2(9.5)$ & $10(8.3)$ & \\
\hline \multirow[t]{4}{*}{ Primary tumor location } & Upper third & $4(13.8)$ & $23(20.5)$ & 0.70 & $2(9.5)$ & $25(20.8)$ & 0.24 \\
\hline & Middle third & $16(55.2)$ & $55(49.1)$ & & $14(66.7)$ & $57(47.5)$ & \\
\hline & Lower third and & & & & & & \\
\hline & esophagogastric junction & $9(31.0)$ & $34(30.4)$ & & $5(23.8)$ & $38(31.7)$ & \\
\hline \multirow[t]{2}{*}{ Tumor differentiation (biopsy) } & Poor & $13(44.8)$ & $40(35.7)$ & 0.59 & $9(42.9)$ & $44(36.7)$ & 0.59 \\
\hline & Other & $16(55.2)$ & $62(55.4)$ & & $12(57.1)$ & $76(63.3)$ & \\
\hline Carcinoembryonic antigen, $\mathrm{ng} / \mathrm{ml}$ & Mean \pm SD & $4.5 \pm 4.6$ & $3.1 \pm 2.0$ & 0.02 & $3.7 \pm 2.9$ & $3.3 \pm 2.8$ & 0.52 \\
\hline SCC-related antigen, $\mathrm{ng} / \mathrm{mI}$ & Mean \pm SD & $2.0 \pm 2.2$ & $2.0 \pm 2.3$ & 0.99 & $1.9 \pm 2.3$ & $2.1 \pm 2.3$ & 0.80 \\
\hline \multirow{2}{*}{$\mathrm{cT}^{*}$} & $1 / 2$ & $2(6.9)$ & $19(17.0)$ & 0.17 & $1(4.8)$ & $20(16.7)$ & 0.16 \\
\hline & $3 / 4$ & $27(93.1)$ & $93(83.0)$ & & $20(95.2)$ & $100(83.3)$ & \\
\hline \multirow[t]{2}{*}{$\mathrm{cN}^{*}$} & $0 / 1$ & $20(69.0)$ & $90(80.4)$ & 0.19 & $17(81.0)$ & $93(77.5)$ & 0.72 \\
\hline & $2 / 3$ & $9(31.0)$ & $22(19.6)$ & & $4(19.0)$ & $27(22.5)$ & \\
\hline \multirow[t]{2}{*}{$\mathrm{cM}^{*}$} & 0 & $24(82.8)$ & $99(88.4)$ & 0.42 & $18(85.7)$ & $105(87.5)$ & 0.82 \\
\hline & 1 & $5(17.2)$ & $13(11.6)$ & & $3(14.3)$ & $15(12.5)$ & \\
\hline \multicolumn{8}{|l|}{ Operative } \\
\hline \multirow[t]{2}{*}{ Thoracic surgical procedure } & Open thoracotomy & $24(82.8)$ & $99(88.4)$ & 0.42 & $17(81.0)$ & $106(88.3)$ & 0.35 \\
\hline & Thoracoscopic surgery & $5(17.2)$ & $13(11.6)$ & & $4(19.0)$ & $14(11.7)$ & \\
\hline \multirow[t]{2}{*}{ Lymph node dissection } & Two-field & $9(31.0)$ & $37(33.0)$ & 0.84 & $8(38.1)$ & $38(31.7)$ & 0.56 \\
\hline & Three-field & $20(69.0)$ & $75(67.0)$ & & $13(61.9)$ & $82(76.7)$ & \\
\hline Surgical duration, min & Mean \pm SD & $457 \pm 78$ & $441 \pm 89$ & 0.34 & $455 \pm 90$ & $442 \pm 87$ & 0.53 \\
\hline Blood loss, g & Mean \pm SD & $600 \pm 480$ & $578 \pm 505$ & 0.83 & $619 \pm 507$ & $576 \pm 499$ & 0.71 \\
\hline \multirow[t]{2}{*}{ Blood transfusion } & Yes & $8(27.6)$ & $28(25.0)$ & 0.78 & $8(38.1)$ & $28(23.3)$ & 0.15 \\
\hline & No & $21(72.4)$ & $84(75.0)$ & & $13(61.9)$ & $92(76.7)$ & \\
\hline \multirow[t]{2}{*}{ Postoperative complications $\ddagger$} & $\geq$ Grade $3 b$ & $6(20.7)$ & $8(7.1)$ & 0.03 & $6(28.6)$ & $8(6.7)$ & 0.002 \\
\hline & $<$ Grade $3 b$ & $23(79.3)$ & $104(92.9)$ & & $15(71.4)$ & $112(93.3)$ & \\
\hline \multirow[t]{2}{*}{ Postoperative infectious complications } & Yes & $11(37.9)$ & $38(33.9)$ & 0.95 & $9(42.9)$ & $40(33.3)$ & 0.40 \\
\hline & No & $18(62.1)$ & $64(57.1)$ & & $12(57.1)$ & $80(66.7)$ & \\
\hline \multicolumn{8}{|l|}{ Pathological } \\
\hline \multirow[t]{2}{*}{ урт** } & $0 / 1$ & $8(27.6)$ & $63(56.3)$ & 0.01 & $6(28.6)$ & $65(54.2)$ & 0.03 \\
\hline & $2 / 3 / 4$ & $21(72.4)$ & $49(43.8)$ & & $15(71.4)$ & $55(45.8)$ & \\
\hline \multirow[t]{2}{*}{ ypN** } & $0 / 1$ & $17(58.6)$ & $104(92.9)$ & $<0.001$ & $13(61.9)$ & $108(90.0)$ & 0.001 \\
\hline & $2 / 3$ & $12(41.4)$ & $8(7.1)$ & & $8(38.1)$ & $12(10.0)$ & \\
\hline $\mathrm{ypM}^{* * \#}$ & 0 & $26(89.7)$ & $109(97.3)$ & 0.07 & $19(90.5)$ & $116(96.7)$ & 0.19 \\
\hline & 1 & $3(10.3)$ & $3(2.7)$ & & $2(9.5)$ & $4(3.3)$ & \\
\hline Tumor differentiation (resected specimen) & Poor & $10(34.5)$ & $23(20.5)$ & 0.11 & $9(42.9)$ & $24(20.0)$ & 0.02 \\
\hline & Other & $19(65.5)$ & $89(79.5)$ & & $12(57.1)$ & $96(80.0)$ & \\
\hline Lymphatic invasion & With & $16(55.2)$ & $20(17.9)$ & $<0.0001$ & $10(47.6)$ & $26(21.7)$ & 0.01 \\
\hline & Without & $13(44.8)$ & $92(82.1)$ & & $11(52.4)$ & $94(78.3)$ & \\
\hline Venous invasion & With & $8(27.6)$ & $9(8.0)$ & 0.004 & $7(33.3)$ & $10(8.3)$ & 0.001 \\
\hline & Without & $21(72.4)$ & $103(92.0)$ & & $14(66.7)$ & $110(91.7)$ & \\
\hline Pathological response of primary tumor & $\mathrm{pCR}$ & $6(20.7)$ & $48(42.9)$ & 0.03 & $5(23.8)$ & $49(40.8)$ & 0.14 \\
\hline & Non-pCR & $23(79.3)$ & $64(57.1)$ & & $16(76.2)$ & $71(59.2)$ & \\
\hline
\end{tabular}

ECOG PS: Eastern Cooperative Oncology Group performance status; pCR, pathological complete response; SCC: squamous cell carcinoma; SD: standard deviation. *Pretherapeutic/**pathological according to TNM Classification, 7th edition (16). \#ccording to Clavien-Dindo classification (17). "Supraclavicular lymph node metastasis.

analyses found ypN2/3 to be a risk factor for early recurrence, and that severe postoperative complications and pathological venous invasion were risk factors for early cancer death. Although a relatively small number of patients had these risk factors, such patients had extremely poor prognoses even after intensive multimodal therapy.

Various clinicopathological factors have been reported as risky for early recurrence or cancer death in patients with 
Table III. Multivariate analysis of factors associated with early recurrence and cancer death.

\begin{tabular}{|c|c|c|c|}
\hline \multirow[t]{2}{*}{ Variable } & \multicolumn{3}{|c|}{ Multivariate analysis } \\
\hline & HR & $95 \% \mathrm{CI}$ & $p$-Value \\
\hline \multicolumn{4}{|c|}{ Early recurrence } \\
\hline \multicolumn{4}{|c|}{ Carcinoembryonic antigen } \\
\hline Continuous & 1.12 & $0.93-1.34$ & 0.25 \\
\hline \multicolumn{4}{|c|}{ Postoperative complications $\ddagger$} \\
\hline$<$ Grade 3b & 1 & & \\
\hline$\geq$ Grade $3 b$ & 2.78 & $0.68-11.41$ & 0.16 \\
\hline \multicolumn{4}{|l|}{ ypT* } \\
\hline $0 / 1$ & 1 & & \\
\hline $2 / 3 / 4$ & 1.99 & $0.37-10.70$ & 0.43 \\
\hline \multicolumn{4}{|l|}{ ypN* } \\
\hline $0 / 1$ & 1 & & \\
\hline $2 / 3$ & 4.13 & $1.25-13.66$ & 0.02 \\
\hline \multicolumn{4}{|c|}{$\begin{array}{l}\text { Pathological response } \\
\text { of primary tumor }\end{array}$} \\
\hline $\mathrm{pCR}$ & 1 & & \\
\hline Non-pCR & 1.75 & $0.28-10.78$ & 0.55 \\
\hline \multicolumn{4}{|c|}{ Lymphatic invasion } \\
\hline Without & 1 & & \\
\hline With & 2.34 & $0.71-7.77$ & 0.17 \\
\hline \multicolumn{4}{|c|}{ Venous invasion } \\
\hline Without & 1 & & \\
\hline With & 2.42 & $0.65-8.99$ & 0.19 \\
\hline \multicolumn{4}{|c|}{ Early cancer death } \\
\hline \multicolumn{4}{|c|}{ Postoperative complications } \\
\hline$<$ Grade $3 b$ & 1 & & \\
\hline$\geq$ Grade $3 b$ & 5.99 & $1.53-23.47$ & 0.01 \\
\hline \multicolumn{4}{|c|}{$\begin{array}{l}\text { Tumor differentiation } \\
\text { (resected specimen) }\end{array}$} \\
\hline Other & 1 & & \\
\hline Poor & 2.05 & $0.65-6.51$ & 0.22 \\
\hline \multicolumn{4}{|l|}{$\mathrm{ypT}^{*}$} \\
\hline $0 / 1$ & 1 & & \\
\hline $2 / 3 / 4$ & 1.21 & $0.33-4.48$ & 0.78 \\
\hline \multicolumn{4}{|l|}{ ypN* } \\
\hline $0 / 1$ & 1 & & \\
\hline $2 / 3$ & 3.44 & $0.94-12.66$ & 0.06 \\
\hline \multicolumn{4}{|c|}{ Lymphatic invasion } \\
\hline Without & 1 & & \\
\hline With & 1.08 & $0.27-4.28$ & 0.92 \\
\hline \multicolumn{4}{|c|}{ Venous invasion } \\
\hline Without & 1 & & \\
\hline With & 4.80 & $1.21-19.14$ & 0.03 \\
\hline
\end{tabular}

CI: Confidence interval; HR: hazard ratio; pCR: pathological complete response. ¥According to Clavien-Dindo classification (17). *Pathological staging according to TNM classification, 7th edition (16).

esophageal cancer. Preoperative smoking, increased Creactive protein levels before treatment, postoperative complications, poor tumor differentiation, increased tumor depth of invasion, pathological venous invasion, microscopically incomplete resection (R1), increased positive-to-resected lymph node ratio and extracapsular lymph node involvement are associated with early recurrence
Table IV. Relationships between early recurrence or cancer death and their risk factors.

\begin{tabular}{|c|c|c|c|}
\hline \multirow[t]{2}{*}{ Parameter } & \multicolumn{2}{|c|}{ Frequency, n (\%) } & \multirow[t]{2}{*}{$p$-Value } \\
\hline & Yes & No & \\
\hline $\begin{array}{l}\text { Early recurrence } \\
\mathrm{ypN}^{*}\end{array}$ & $(n=29)$ & $(\mathrm{n}=112)$ & \\
\hline $0 / 1$ & $17(14.0)$ & $104(86.0)$ & $<0.0001$ \\
\hline $2 / 3$ & $12(60.0)$ & $8(40.0)$ & \\
\hline Early cancer death & $(n=21)$ & $(n=120)$ & \\
\hline \multicolumn{4}{|l|}{ Postoperative complications $\ddagger$} \\
\hline$<$ Grade $3 b$ & $15(11.8)$ & $112(88.2)$ & 0.002 \\
\hline$\geq$ Grade $3 b$ & $6(42.9)$ & $8(57.1)$ & \\
\hline \multicolumn{4}{|l|}{ VI } \\
\hline Without & $14(11.3)$ & $110(88.7)$ & 0.001 \\
\hline With & $7(41.2)$ & $10(58.8)$ & \\
\hline \multicolumn{4}{|c|}{ Postoperative complications $\ddagger$ and VI } \\
\hline$<$ Grade 3b, no VI & $9(8.1)$ & $102(91.9)$ & $<0.0001$ \\
\hline$\geq$ Grade $3 \mathrm{~b}$ and/or with VI & $12(40.0)$ & $18(60.0)$ & \\
\hline
\end{tabular}

VI: Venous invasion. *Pathological staging according to TNM classification, 7th edition (16). $¥$ According to Clavien-Dindo classification (17).

after esophagectomy (7, 13, 14). Furthermore, poor performance status ( 1 or 2 ), lack of response to neoadjuvant therapy, intramural metastasis, microscopically and macroscopically incomplete resection ( $\mathrm{R} 1$ or 2), increased tumor depth of invasion, increased lymph node metastases, and poor tumor differentiation are associated with early cancer death (8-12). These reports describe patients with several histological types of esophageal cancer (ESCC or adenocarcinoma), various surgical strategies (transthoracic, trans-hiatal or left thoracotomy) and treatment modalities (surgery alone or neoadjuvant therapy followed by surgery). Therefore, the risk factors for early recurrence and death might somewhat differ among studies.

Pathological LN metastasis is an important prognostic factor for esophageal cancer treated with NCRT followed by surgery $(5,24,25)$. The present multivariate analysis selected ypN2/3 as the only significant independent risk factor for early recurrence and showed that it also tended to be a risk factor for early cancer death $(p=0.06)$. Disease in patients with multiple pathological LN metastases even after NCRT might be considered resistant to chemotherapy and radiotherapy. Furthermore, they have a very high probability of unrecognized occult metastases during treatment. Therefore, postoperative therapy, preferably with anticancer drugs that differ from those used in NCRT, should be carefully considered for patients with multiple pathological $\mathrm{LN}$ metastases in order to delay and reduce recurrence after trimodal therapy. Such patients also require meticulous surveillance to detect early recurrence.

Lymphatic and venous invasion are independent prognostic factors for survival after initial surgical resection of ESCC (26- 

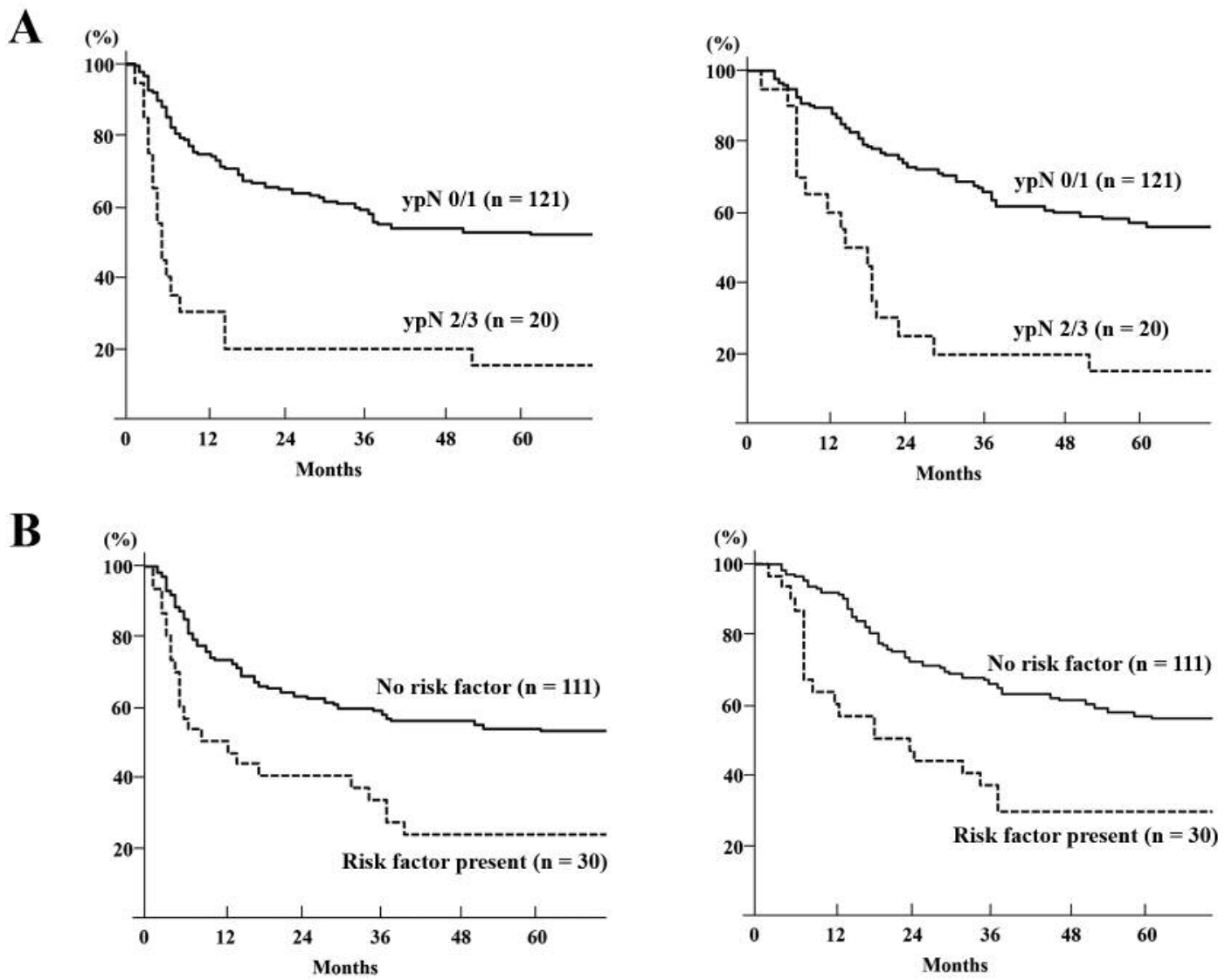

Figure 1. Recurrence-free (RFS; left panel) and overall (OS; right panel) survival of patients with esophageal squamous cell carcinoma after trimodal therapy according to the presence of risk factors [pathological nodal staging (ypN), postoperative complications, and venous invasion] associated with early recurrence and early cancer death. A: Survival rates of patients according to ypN as a risk factor for early recurrence $(p<0.0001)$. B: Survival rates of patients with Clavien-Dindo grade $\geq 3$ bostoperative complications with/without venous invasion compared with those with neither of them as risk factors for early cancer death (RFS: $p=0.0004$; OS: $p=0.001$ ).

28) and after neoadjuvant therapy followed by surgery (29-31). Among these reports, lymphovascular invasion had prognostic value in patients with ESCC treated by NCRT followed by surgery, which are the same histological type and treatment modality as the present study $(30,31)$. Therefore, lymphatic/vascular invasion is very important for the prognosis of esophageal cancer, not only after surgery, but also after neoadjuvant therapy followed by surgery. However, the present findings indicated that venous invasion might be more important than lymphatic invasion, especially in terms of early cancer death among patients with ESCC after trimodal therapy.

Esophageal surgery is highly invasive, and postoperative complications reportedly have an important prognostic impact on patients with esophageal cancer $(14,32-34)$. The implications of postoperative complications with respect to prognosis of patients with esophageal cancer are associated with various issues such as poor general status before treatment, inherent immunological capacity and immunocompromised status, poor nutrition and insufficient therapy after recurrence according to an overall decline in general status induced by severe postoperative complications. The relationship between severe postoperative complications and early cancer death might be attributable to complex interactions and effects of these factors. Therefore, minimally invasive surgery should focus on reducing postoperative complications.

Risk factors for early recurrence and early cancer death have not previously been concurrently evaluated as far as we are aware. We assessed both these factors in a single patient cohort and found that multivariate analyses selected significant factors that differed between early recurrence and death. This finding indicates that important prognostic factors might somewhat change before and after recurrence. These factors might be closely associated with complex combined causes of malignant tumor potential, occult cancer after macroscopically curative surgery, being refractory to 
chemo- or radiation therapy, and being difficult to treat after recurrence. Taken together, the prognosis of patients with ypN2/3, venous invasion and severe postoperative complications after trimodal therapy for ESCC was significantly poor.

The retrospective design is a limitation of the present study and another is that the chemotherapy regimens varied at different times during the study period. Nonetheless, the present study included a relatively large cohort of uniform patients with locally advanced ESCC who all underwent NCRT with 40 Gy of radiation followed by surgery with adequate $\mathrm{LN}$ dissection.

We conclude that $\mathrm{ypN} 2 / 3$ is a risk factor for early recurrence, whereas severe postoperative complications and venous invasion are risk factors for early cancer death after trimodal therapy for ESCC. Further prevention of postoperative complications is needed for patients with esophageal cancer, and meticulous surveillance is needed especially for those with risk factors for early recurrence and cancer death. Postoperative adjuvant therapy should be considered for such patients, in consideration of their general condition after trimodal therapy.

\section{Conflicts of Interest}

The Authors have no commercial support or conflicts of interest to disclose in regard to this study.

\section{Authors' Contributions}

Conception and design: Yoichi Hamai and Morihito Okada. Contribution to patient care: Yuji Murakami, Ikuno Nishibuchi, Yasushi Nagata, Takaoki Furukawa, Tomoaki Kurokawa and Manato Ohsawa. Collection and assembly of data: Yoichi Hamai, Manabu Emi and Yuta Ibuki. Data analysis and interpretation: Yoichi Hamai, Manabu Emi and Yuji Murakami. Manuscript writing: Yoichi Hamai. Final approval of manuscript: All Authors.

\section{References}

1 Sjoquist KM, Burmeister BH, Smithers BM, Zalcberg JR, Simes RJ, Barbour A and Gebski V; Australasian Gastro-Intestinal Trials Group: Survival after neoadjuvant chemotherapy or chemoradiotherapy for resectable oesophageal carcinoma: An updated meta-analysis. Lancet Oncol 12: 681-692, 2011. PMID: 21684205. DOI: 10.1016/S1470-2045(11)70142-5

2 Tepper J, Krasna MJ, Niedzwiecki D, Hollis D, Reed CE, Goldberg R, Kiel K, Willett C, Sugarbaker D and Mayer R: Phase III trial of trimodal therapy with cisplatin, fluorouracil, radiotherapy, and surgery compared with surgery alone for esophageal cancer: CALGB 9781. J Clin Oncol 26: 1086-1092, 2008. PMID: 18309943. DOI: 10.1200/JCO.2007.12.9593

3 van Hagen P, Hulshof MC, van Lanschot JJ, Steyerberg EW, van Berge Henegouwen MI, Wijnhoven BP, Richel DJ, Nieuwenhuijzen GA, Hospers GA, Bonenkamp JJ, Cuesta MA, Blaisse RJ, Busch OR, ten Kate FJ, Creemers GJ, Punt CJ, Plukker JT, Verheul HM, Spillenaar Bilgen EJ, van Dekken H, van der Sangen MJ, Rozema T, Biermann K, Beukema JC, Piet $\mathrm{AH}$, van Rij CM, Reinders JG, Tilanus HW and van der Gaast A; CROSS Group: Preoperative chemoradiotherapy for esophageal or junctional cancer. N Engl J Med 366: 2074-2084, 2012. PMID: 22646630. DOI: 10.1056/NEJMoa1112088

4 Hamai Y, Hihara J, Emi M, Murakami Y, Kenjo M, Nagata Y and Okada M: Results of neoadjuvant chemoradiotherapy with docetaxel and 5-fluorouracil followed by esophagectomy to treat locally advanced esophageal cancer. Ann Thorac Surg 99: 18871893, 2015. PMID: 25912745. DOI: 10.1016/j.athoracsur. 2015.02.042

5 Hamai Y, Hihara J, Emi M, Furukawa T, Murakami Y, Nishibuchi I, Ibuki Y, Yamakita I, Kurokawa T, Nagata Y and Okada M: Evaluation of prognostic factors for esophageal squamous cell carcinoma treated with neoadjuvant chemoradiotherapy followed by surgery. World J Surg 42: 1496-1505, 2018. PMID: 29030675. DOI: $10.1007 / \mathrm{s} 00268-017-4283-1$

6 Murakami Y, Hamai Y, Emi M, Hihara J, Imano N, Takeuchi Y, Takahashi I, Nishibuchi I, Kimura T, Okada M and Nagata Y: Long-term results of neoadjuvant chemoradiotherapy using cisplatin and 5-fluorouracil followed by esophagectomy for resectable, locally advanced esophageal squamous cell carcinoma. J Radiat Res 59: 616-624, 2018. PMID: 29939306. DOI: $10.1093 / \mathrm{jrr} / \mathrm{rry} 047$

7 Yoshida N, Baba Y, Shigaki H, Harada K, Iwatsuki M, Sakamoto Y, Miyamoto Y, Kurashige J, Kosumi K, Tokunaga R, Watanabe $\mathrm{M}$ and Baba H: Risk factors of early recurrence within 6 months after esophagectomy following neoadjuvant chemotherapy for resectable advanced esophageal squamous cell carcinoma. Int $\mathbf{J}$ Clin Oncol 21: 1071-1078, 2016. PMID: 27255393. DOI: 10.1007/s10147-016-0994-9

8. Stiles BM, Salzler GG, Nasar A, Paul S, Lee PC, Port JL and Altorki NK: Clinical predictors of early cancer-related mortality following neoadjuvant therapy and oesophagectomy. Eur J Cardiothorac Surg 48: 455-460, 2015. PMID: 25564218. DOI: 10.1093/ejcts/ezu479

9 Zhu ZJ, Hu Y, Zhao YF, Chen XZ, Chen LQ and Chen YT: Early recurrence and death after esophagectomy in patients with esophageal squamous cell carcinoma. Ann Thorac Surg 91: 1502-1508, 2011. PMID: 21354552. DOI: 10.1016/j.athoracsur. 2011.01.007

10 Davies AR, Pillai A, Sinha P, Sandhu H, Adeniran A, Mattsson F, Choudhury A, Forshaw MJ, Gossage JA, Lagergren J, Allum WH and Mason RC: Factors associated with early recurrence and death after esophagectomy for cancer. J Surg Oncol 109: 459-464, 2014. PMID: 24301461. DOI: 10.1002/jso.23511

11 Kosugi S, Kanda T, Yajima K, Ishikawa T and Hatakeyama K: Risk factors that influence early death due to cancer recurrence after extended radical esophagectomy with three-field lymph node dissection. Ann Surg Oncol 18: 2961-2967, 2011. PMID: 21499809. DOI: $10.1245 / \mathrm{s} 10434-011-1712-5$

12 Matsumoto S, Takayama T, Wakatsuki K, Enomoto K, Tanaka T, Migita K, Ito $M$ and Nakajima Y: Predicting early cancerrelated deaths after curative esophagectomy for esophageal cancer. Am Surg 79: 528-533, 2013. PMID: 23635590.

13 Mantziari S, Allemann P, Winiker M, Demartines N and Schäfer $\mathrm{M}$ : Locoregional tumor extension and preoperative smoking are significant risk factors for early recurrence after esophagectomy for cancer. World J Surg 42: 2209-2217, 2018. PMID: 29282511. DOI: $10.1007 / \mathrm{s} 00268-017-4422-8$ 
14 Lerut T, Moons J, Coosemans W, Van Raemdonck D, De Leyn P, Decaluwé H, Decker G and Nafteux P: Postoperative complications after transthoracic esophagectomy for cancer of the esophagus and gastroesophageal junction are correlated with early cancer recurrence: Role of systematic grading of complications using the modified Clavien classification. Ann Surg 250: 798-807, 2009. PMID: 19809297. DOI: 10.1097/ SLA.0b013e3181bdd5a8

15 Oken MM, Creech RH, Tormey DC, Horton J, Davis TE, McFadden ET and Carbone PP: Toxicity and response criteria of the Eastern Cooperative Oncology Group. Am J Clin Oncol 5: 649-655, 1982. PMID: 7165009.

16 International Union Against Cancer (UICC): TNM Classification of Malignant Tumours (7th edition). Sobin L, Gospodarowicz M and Wittekind C (eds.). Wiley: New York, 2009.

17 Dindo D, Demartines N and Clavien PA: Classification of surgical complications: A new proposal with evaluation in a cohort of 6336 patients and results of a survey. Ann Surg 240: 205-213, 2004. PMID: 15273542.

18 Clavien PA, Barkun J, de Oliveira ML, Vauthey JN, Dindo D, Schulick RD, de Santibañes E, Pekolj J, Slankamenac K, Bassi C, Graf R, Vonlanthen R, Padbury R, Cameron JL and Makuuchi M: The Clavien-Dindo classification of surgical complications: five-year experience. Ann Surg 250: 187-196, 2009. PMID: 19638912. DOI: 10.1097/SLA.0b013e3181b13ca2

19 Hamai Y, Hihara J, Emi M, Furukawa T, Yamakita I, Kurokawa $\mathrm{T}$ and Okada M: Ability of fluorine-18 fluorodeoxyglucose positron emission tomography to predict outcomes of neoadjuvant chemoradiotherapy followed by surgical treatment for esophageal squamous cell carcinoma. Ann Thorac Surg 102: 1132-1139, 2016. PMID: 27319990. DOI: 10.1016/ j.athoracsur.2016.04.011

20 Hamai Y, Hihara J, Taomoto J, Yamakita I, Ibuki Y and Okada M: Hemoglobin level influences tumor response and survival after neoadjuvant chemoradiotherapy for esophageal squamous cell carcinoma. World J Surg 38: 2046-2051, 2014. PMID: 24615604. DOI: 10.1007/s00268-014-2486-2

21 Emi M, Hihara J, Hamai Y, Aoki Y, Okada M, Kenjo M and Murakami Y: Neoadjuvant chemoradiotherapy with docetaxel, cisplatin, and 5-fluorouracil for esophageal cancer. Cancer Chemother Pharmacol 69: 1499-1505, 2012. PMID: 22382882. DOI: $10.1007 / \mathrm{s} 00280-012-1853-7$

22 Hamai Y, Hihara J, Taomoto J, Yamakita I, Ibuki Y and Okada M: Effects of neoadjuvant chemoradiotherapy on postoperative morbidity and mortality associated with esophageal cancer. Dis Esophagus 28: 358-364, 2015. PMID: 24612033. DOI: $10.1111 /$ dote 12207

23 Hamai Y, Hihara J, Emi M, Furukawa T, Ibuki Y, Yamakita I, Kurokawa $\mathrm{T}$ and Okada $\mathrm{M}$ : Effects of neoadjuvant chemoradiotherapy on pathological TNM stage and their prognostic significance for surgically-treated esophageal squamous cell carcinoma. Anticancer Res 37: 5639-5646, 2017. PMID: 28982881. DOI: 10.21873/anticanres.11999

24 Miyata H, Yamasaki M, Takiguchi S, Nakajima K, Fujiwara Y, Mori M and Doki Y: Pre-and post-therapy nodal status equally affects survival of patients with oesophageal squamous cell carcinoma receiving preoperative chemoradiation. Oncol Rep 23: 1331-1337, 2010. PMID: 20372848.

25 Akutsu Y, Shuto K, Kono T, Uesato M, Hoshino I, Shiratori T, Isozaki Y, Akanuma N, Uno $\mathrm{T}$ and Matsubara $\mathrm{H}$ : The number of pathologic lymph nodes involved is still a significant prognostic factor even after neoadjuvant chemoradiotherapy in esophageal squamous cell carcinoma. J Surg Oncol 105: 756-760, 2012. PMID: 22162007. DOI: 10.1002/jso.23007

26 Brücher BL, Stein HJ, Werner M and Siewert JR: Lymphatic vessel invasion is an independent prognostic factor in patients with a primary resected tumor with esophageal squamous cell carcinoma. Cancer 92: 2228-2233, 2001. PMID: 11596042.

27 Zhu CM, Ling YH, Xi SY, Luo RZ, Chen JW, Yun JP, Xie D and Cai MY: Prognostic significance of the $\mathrm{pN}$ classification supplemented by vascular invasion for esophageal squamous cell carcinoma. PLoS One 9: e96129, 2014. PMID: 24763284. DOI: 10.1371/journal.pone.0096129

28 Jeon JH, Lee JM, Moon DH, Yang HC, Kim MS, Lee GK and Zo JI: Prognostic significance of venous invasion and maximum standardized uptake value of 18F-FDG PET/CT in surgically resected T1N0 esophageal squamous cell carcinoma. Eur J Surg Oncol 43: 471-477, 2017. PMID: 27912930. DOI: 10.1016/ j.ejso.2016.11.002

29 Hatogai K, Fujii S, Kojima T, Daiko H, Kadota T, Fujita T, Yoshino T, Doi T, Takiguchi $\mathrm{Y}$ and Ohtsu A: Prognostic significance of tumor regression grade for patients with esophageal squamous cell carcinoma after neoadjuvant chemotherapy followed by surgery. J Surg Oncol 113: 390-396, 2016. PMID: 27100024. DOI: 10.1002/jso.24151

30 Chen WH, Huang YL, Chao YK, Yeh CJ, Chang HK, Tseng CK and Liu YH: Prognostic significance of lymphovascular invasion in patients with esophageal squamous cell carcinoma treated with neoadjuvant chemoradiotherapy. Ann Surg Oncol 22: 3383843, 2015. PMID: 25023545. DOI: 10.1245/s10434-014-38815

31 Tu CC, Hsu PK, Chien LI, Liu WC, Huang CS, Hsieh CC, Hsu HS and Wu YC: Prognostic histological factors in patients with esophageal squamous cell carcinoma after preoperative chemoradiation followed by surgery. BMC Cancer 17: 62, 2017. PMID: 28103913. DOI: 10.1186/s12885-017-3063-5

32 Saeki H, Tsutsumi S, Tajiri H, Yukaya T, Tsutsumi R, Nishimura S, Nakaji Y, Kudou K, Akiyama S, Kasagi Y, Nakanishi R, Nakashima Y, Sugiyama M, Ohgaki K, Sonoda H, Oki E and Maehara Y: Prognostic significance of postoperative complications after curative resection for patients with esophageal squamous cell carcinoma. Ann Surg 265: 527-533, 2017. PMID: 28169928. DOI: 10.1097/SLA.0000000000001692

33 Kataoka K, Takeuchi H, Mizusawa J, Igaki H, Ozawa S, Abe T, Nakamura K, Kato K, Ando N and Kitagawa Y: Prognostic impact of postoperative morbidity after esophagectomy for esophageal cancer: exploratory analysis of JCOG9907. Ann Surg 265: 1152-1157, 2017. PMID: 27280509. DOI: 10.1097/ SLA.0000000000001828

34 Luc G, Durand M, Chiche L and Collet D: Major post-operative complications predict long-term survival after esophagectomy in patients with adenocarcinoma of the esophagus. World J Surg 39: 216-222, 2015. PMID: 25189448. DOI: 10.1007/s00268014-2754-1 